\title{
Novel Alhagi maurorum leaves mediated synthesis of titanium nanoparticles for human breast carcinoma applications: a preclinical trial
}

\section{Type}

Research paper

\section{Keywords}

Green synthesis, Titanium nanoparticles, Alhagi maurorum leaf, Chemical characterization, Human breast cancer

\begin{abstract}
Introduction

In this study, titanium nanoparticles (TiNPs) were synthesized in an aqueous medium using Alhagi maurorum extract as stabilizing and reducing agents.

\section{Material and methods}

Ultraviolet-visible spectrophotometry (UV-Vis), fourier-transform infrared spectroscopy (FTIR), $X \square$ ray diffraction (XRD), scanning electron microscopy (SEM), and Energy Dispersive X-ray Spectrometry (EDS) were the techniques to characterize the biosynthetic of TiNPs. According to the XRD analysis. To survey the anti-human breast cancer effects of TiNPs, MTT assay was used on the common breast cancer cell lines i.e., breast cancer (Breast adenocarcinoma (MCF7), infiltrating ductal cell carcinoma (Hs 319.T), inflammatory carcinoma of the breast (UACC-732), and metastatic carcinoma (MDA-MB-453) cell lines.
\end{abstract}

\section{Results}

$16.08 \mathrm{~nm}$ was measured for TiNPs crystal size. SEM images exhibited a uniform spherical morphology in range size of 12.16 to $43.46 \mathrm{~nm}$ for the biosynthesized nanoparticles respectively. The cell viability of breast carcinoma cells decreased dose-dependently in the titanium nanoparticles presence. The IC50 of A. maurorum and titanium particles on MCF7 cell line were 680 and 359 $\mu \mathrm{g} / \mathrm{mL}$, on Hs 319.T cell line were 507 and $191 \mu \mathrm{g} / \mathrm{mL}$, on UACC-732 cell line were 477 and 217 $\mu \mathrm{g} / \mathrm{mL}$, and on MDA-MB-453cell line were 507 and $191 \mu \mathrm{g} / \mathrm{mL}$, respectively. TiNPs had high antibreast cancer activities dose-dependently against MCF7, Hs 319.T, UACC-732, and MDA-MB-453 cell lines.

\section{Conclusions}

The best result of anti-breast cancer effects was seen in the case of the Hs 319.T cell line. 


\title{
Novel Alhagi maurorum leaves mediated synthesis of titanium nanoparticles for human breast carcinoma applications: a preclinical trial study
}

\begin{abstract}
In this study, titanium nanoparticles (TiNPs) were synthesized in an aqueous medium using Alhagi maurorum extract as stabilizing and reducing agents. Ultraviolet-visible spectrophotometry (UV-Vis), fourier-transform infrared spectroscopy (FTIR), X-ray diffraction (XRD), scanning electron microscopy (SEM), and Energy Dispersive X-ray Spectrometry (EDS) were the techniques to characterize the biosynthetic of TiNPs. According to the XRD analysis. To survey the anti-human breast cancer effects of TiNPs, MTT assay was used on the common breast cancer cell lines i.e., breast cancer (Breast adenocarcinoma (MCF7), infiltrating ductal cell carcinoma (Hs 319.T), inflammatory carcinoma of the breast (UACC-732), and metastatic carcinoma (MDA-MB-453)) cell lines. $16.08 \mathrm{~nm}$ was measured for TiNPs crystal size. SEM images exhibited a uniform spherical morphology in range size of 12.16 to $43.46 \mathrm{~nm}$ for the biosynthesized nanoparticles respectively. The cell viability of breast carcinoma cells decreased dosedependently in the titanium nanoparticles presence. The IC50 of A. maurorum and titanium particles on MCF7 cell line were 680 and $359 \mu \mathrm{g} / \mathrm{mL}$, on Hs 319.T cell line were 507 and $191 \mu \mathrm{g} / \mathrm{mL}$, on UACC-732 cell line were 477 and $217 \mu \mathrm{g} / \mathrm{mL}$, and on MDA-MB453cell line were 507 and $191 \mu \mathrm{g} / \mathrm{mL}$, respectively. TiNPs had high anti-breast cancer activities dose-dependently against MCF7, Hs 319.T, UACC-732, and MDA-MB-453 cell lines. The best result of anti-breast cancer effects was seen in the case of the Hs 319.T cell line.
\end{abstract}

Keywords: Titanium nanoparticles; Alhagi maurorum leaf; Green synthesis; Chemical characterization; Human breast cancer. 


\section{Introduction}

Breast carcinoma is a cancer sort that commences in the breast tissue. Being a woman is the most important risk factor for breast cancer ${ }^{1}$. Although men also get this cancer, women are more than 100 times more likely to get it. Other breast cancer symptoms can include breast deformity, dimples, discharge from the nipple, or scaling of part of the skin. In severe conditions of the disease, these symptoms can include jaundice, breath shortness, swollen lymph nodes, and bone pain 1, 2. Risk factors include the first menstruation at an early age, hormone replacement therapy during menopause, lack of physical exercise, ionizing radiation, drinking alcohol, and obesity ${ }^{2-4}$. Breast cancer treatments are targeted therapy, chemotherapy, radiation therapy, and surgery ${ }^{3,4}$. In people whose cancer has distributed to other body parts, cures are mainly done to improve the quality of life and comfort of the person ${ }^{2,3}$. Raloxifene or Tamoxifen can be administrated to inhibit human breast cancer in people that are more likely to get it ${ }^{5 a-5 e}$. Chemotherapeutic drugs have severe side effects for the patients, so finding new formulations with low side effects are the priority of the Food and Drug Administration. The previous reports have revealed the metallic nanocomposites have unique anticancer efficacies with low side effects ${ }^{5 a-5 e, 6}$.

Nowadays, nanotechnology has been developed in several ways due to its wide range of applications. The applications in medical diagnosis, food, medicine, biotechnology, environment, energy, chemistry, physics, etc. have been considered, which introduces this technology as an interdisciplinary and cross-sectorial field ${ }^{6-8}$. One of the fields of nanotechnology is the production of nanoparticles to prevent and treat various diseases 6 . The tendency to produce nanometer-sized materials and to use them is increasing day by day due to the interesting industrial properties of these materials, but nanoparticles from the chemical procedures used today, because of the hazardous and toxic chemicals use and environmental damage caused by them, they have caused a great deal of concern ${ }^{6,7}$. The production of nanoparticles using the principles of green chemistry has found a special place in research and for this purpose, various types of biological systems are used; microorganisms, diatoms, and optical eukaryotes are among these systems, but these systems are less used due to their high cost of preparation and maintenance ${ }^{9-}$ 
11. Plants and agricultural products have been given special attention as cheap and renewable sources for the preparation of biological nanomaterials ${ }^{6-10}$.

The surface area to volume ratio of nanoparticles makes them potent agents in biological aspects ${ }^{7}$. Metallic nanoparticles with various properties and a wide range of activity have been well known ${ }^{8}$. $\mathrm{TiO}_{2}$ nanoparticles are one of the new metallic nano-compounds with a wide variety of applications in different fields of science. TiNPs have exhibited optical, dielectric, photo-catalytic properties. TiNPs also show biological activity such as anticancer, antibacterial, and antifungal activity ${ }^{9-13}$. These properties depend on different factors such as surface area, morphology, crystallinity, and crystal phase effect on the operational performance of TiNPs ${ }^{14}$.

Traditional medicine refers to health practices, approaches, knowledge and beliefs incorporating plant, animal and mineral based medicines, spiritual therapies, manual techniques and exercises, applied singularly or in combination to treat, diagnose and prevent illnesses or maintain well-being. Traditional medicine has a unique role in producing herbal therapeutic supplements and drugs ${ }^{15-17}$. Alhagi maurorum is an herb with many pharmaceutical properties. It belongs to the Plantae kingdom, Fabales order, Fabaceae family, and Alhagi genus. The several parts of Alhagi maurorum and its products have been used in different world regions for the treatment of diseases such as several cancers, dropsy, rheumatism, asthma, bronchitis, loss of appetite, amenorrhoea, dysmenorrhoea, diarrhea, indigestion, skin eruptions, and worms 18-26. Since ancient times people have used Alhagi maurorum to cure many diseases related to the respiratory, liver function, cardiovascular, gastrointestinal, immune, and urinary, and genital systems 18-20, 22. The chemical antioxidant compounds isolated from Alhagi maurorum are as fallow: 2-nonadecanone, Nonacosane, actinidiolide, 6,10,14trimethyl-2-pentadecanone, trans- $\beta$-ionone, pentacosane, furanacetic acid, 9octylheptadecane, drimenol, squalene, tetracosane, docosane, eicosane, octadecane, and drimenol ${ }^{19-24}$. The therapeutic features of this plant due to its chemical antioxidant composition were mentioned above. 
According to the above explanations, we green-synthesized the titanium nanoparticles using Alhagi maurorum in first, then we measured its anti-breast adenocarcinoma efficacies in vitro condition.

\section{Experimental}

\section{Material}

Bovine serum, antimycotic antibiotic solution, 2,2-diphenyl-1- pikrilhydrazil (DPPH), dimethyl sulfoxide (DMSO), decamplmaneh fetal, 4- (Dimethylamino) benzaldehyde, hydrolyzate, Ehrlich solution, and borax-sulfuric acid mixture, DMED, all were afforded from the US Sigma-Aldrich company.

\section{Extraction of $\boldsymbol{A}$. maurorum leaf aqueous extract}

To obtain the aqueous extract of the plant, $250 \mathrm{gr}$ of the dried branches of the $A$. maurorum leaves were poured into a container containing $2000 \mathrm{~mL}$ boiled water, and the container lid was tightly closed for $4 \mathrm{~h}$. Then, the container's content was filtered, and the remaining liquid was placed on a bain-marie to evaporate. Finally, a tar-like material was obtained, which was powdered by a freeze dryer ${ }^{16}$.

\section{Preparation and synthesis of TiONPs}

A $25 \mathrm{~mL}$ of $A$. maurorum extract $(10 \mathrm{~g} / \mathrm{L})$ was added to $100 \mathrm{ml}$ of $0.1 \mathrm{M}$ aqueous solution of $\mathrm{TiCl}_{4} a t 120^{\circ} \mathrm{C}$ temperature and stirred for $120 \mathrm{~min}$ in the dark. The solution color turned to light brown that indicates the formation of TiNPs. The obtained mixture was incubated for $12 \mathrm{~h}$ at $40^{\circ} \mathrm{C}$. Thereafter the mixture was centrifuged at $10,000 \mathrm{rpm}$ for $20 \mathrm{~min}$ and the 
upper phase was removed. The participate was washed with deionized water three times and once with ethanol ${ }^{27}$.

\section{Chemical Characterization techniques}

TiNPs were characterized by some techniques (UV-Vis., FT-IR, XRD, SEM, and EDS). THERMO UV-vis spectrophotometer (200- 800 nm), Shimadzu FT-IR 8400 (in the range of $400-4000 \mathrm{~cm}^{-1}, \mathrm{KBr}$ disc), GNR EXPLORER instrument (voltage of $40 \mathrm{kV}$, a current of $30 \mathrm{~mA}$, and Cu-Ka radiation $1.5406 \AA$ ), and MIRA3TESCAN-XMU, to report the XRD, FESEM Images and EDS result.

\section{Evaluation of anti-human breast cancer properties of titanium nanoparticles}

The breast cancer (Breast adenocarcinoma (MCF7), infiltrating ductal cell carcinoma (Hs 319.T), inflammatory carcinoma of the breast (UACC-732), and metastatic carcinoma (MDA-MB-453)) cell lines and the normal cell line (HUVEC) in the MTT assay were used as follows. They were in RPMI1640 liquid culture medium containing $10 \%$ inactivated bovine fetal serum (FBS), $2 \mathrm{mM}$ glutamine, solution of penicillin (100 units per $\mathrm{ml}$ ) and streptomycin $(100 \mu \mathrm{g} / \mathrm{ml})$ at $37^{\circ} \mathrm{C}$ and $5 \% \mathrm{CO}_{2}$ and $95 \%$ moisture were cultured and passaged so that the cells reached the desired number in terms of number and morphology (after 3-4 passages). After separating the cells from the flask surface, trypsinEDTA (Gibco BRL, Scotland) counted and evaluated cell viability, and 3,000 cells were cultured in 96-well wells with or without $\mathrm{TiCl}_{4}, A$. maurorum leaf aqueous extract, and titanium nanoparticles. Morphological changes and general characteristics of the cell were assessed 24 hours using an inverted microscope (Motic, AE31 model, China) ${ }^{28}$. 
The effect of cytotoxicity of the $\mathrm{TiCl}_{4}, A$. maurorum leaf aqueous extract, and titanium nanoparticles was evaluated by MTT Methy Thiazol Tetrazolium colorimetric test. MTT (Sigma-Aldrich, USA) is a water-soluble tetrazolium salt based on the activity of living cell mitochondrial dehydrogenase succinate enzyme, which converts the yellow solution of MTT to insoluble purple crystals of formazan (Because the dehydrogenase content of cells of one type is relatively constant, the amount of formazan produced is proportional to the number of cells) Which is soluble in dimethyl sulfoxide ${ }^{28}$.

The cells began to grow in $75 \mathrm{~cm}$ square T-flasks in $15 \mathrm{ml}$ of medium with an initial number of 1-2 10106 cells. After three days and covering the bottom of the flask with the cell, the cell layer adhering to the bottom of the flask was separated enzymatically using trypsinVersen and transferred to a sterile test tube was centrifuged at $1200 \mathrm{rpm}$ for 10 minutes (Germany). Sigma, 3-30k model,). The cells were then resuspended in fresh culture medium with a pasteurizer pipette and $100 \mu \mathrm{l}$ of cell suspension with or without $\mathrm{TiCl}_{4}, A$. maurorum leaf aqueous extract, and titanium nanoparticles were added to each well of the 96-well plate so that there were 3,000 cells in each well. The plates were incubated for 24 hours in an incubator (Germany, Memmert) to return the cells to normal from the stress of trypsinization. Then, suitable dilutions of the desired $\mathrm{TiCl}_{4}, A$. maurorum leaf aqueous extract, and titanium nanoparticles were prepared and $100 \mu \mathrm{l}$ of each dilution was added columnar to the plate wells and the cells were incubated for 37 hours at $37^{\circ}$ $\mathrm{C}$ and $5 \% \mathrm{CO}_{2}$. After 72 hours of adding the $\mathrm{TiCl}_{4}, A$. maurorum leaf aqueous extract, and titanium nanoparticles to the cells, $20 \mu \mathrm{l}$ of $5 \mathrm{mg} / \mathrm{ml} \mathrm{MTT}$ solution was added to each well. The plates were incubated for 4 hours after the required time, the culture medium containing MTT was carefully removed and $100 \mu \mathrm{l}$ of DMSO was added to each well to 
dissolve the resulting formazan. After 10 minutes and shaking the plates using the plate shaker, the light absorption at $570 \mathrm{~nm}$ was read by ELISA Reader (Awareness Technology Inc, Stat Fax 2100, USA). Cells containing no $\mathrm{TiCl}_{4}$, A. maurorum leaf aqueous extract, and titanium nanoparticles were considered as controlled light density and wells without cells and only RPMI1640 medium with bovine fetal serum were considered as blank ${ }^{28}$.

$$
\text { Cell viability }(\%)=\frac{\text { Sample A. }}{\text { Control } A .} \times 100
$$

Finally, linear regression was performed to obtain the IC50 level, which represents the concentration of the extract, which causes $50 \%$ inhibition of cancer cell growth[25]:

\section{Qualitative Measurement}

The obtained findings were analyzed by SPSS (version 20) software using one-way ANOVA, followed by Duncan post-hoc test $(P \leq 0.01)$.

\section{Results and Discussion}

\section{Characterization of TiNPs}

\section{UV-visible spectroscopy analysis}

Fig. 1 presents the UV-Vis. spectrum of biosynthesized TiNPs using A. maurorum extract. The result of UV-Vis. spectroscopy confirms the formation of TiNPs. The peak at $220 \mathrm{~nm}$ belongs to the biosynthetic TiNPs. This observation is in good agreement with the previous report of UV-Vis. for a biosynthesized TiNPs ${ }^{27}$. 


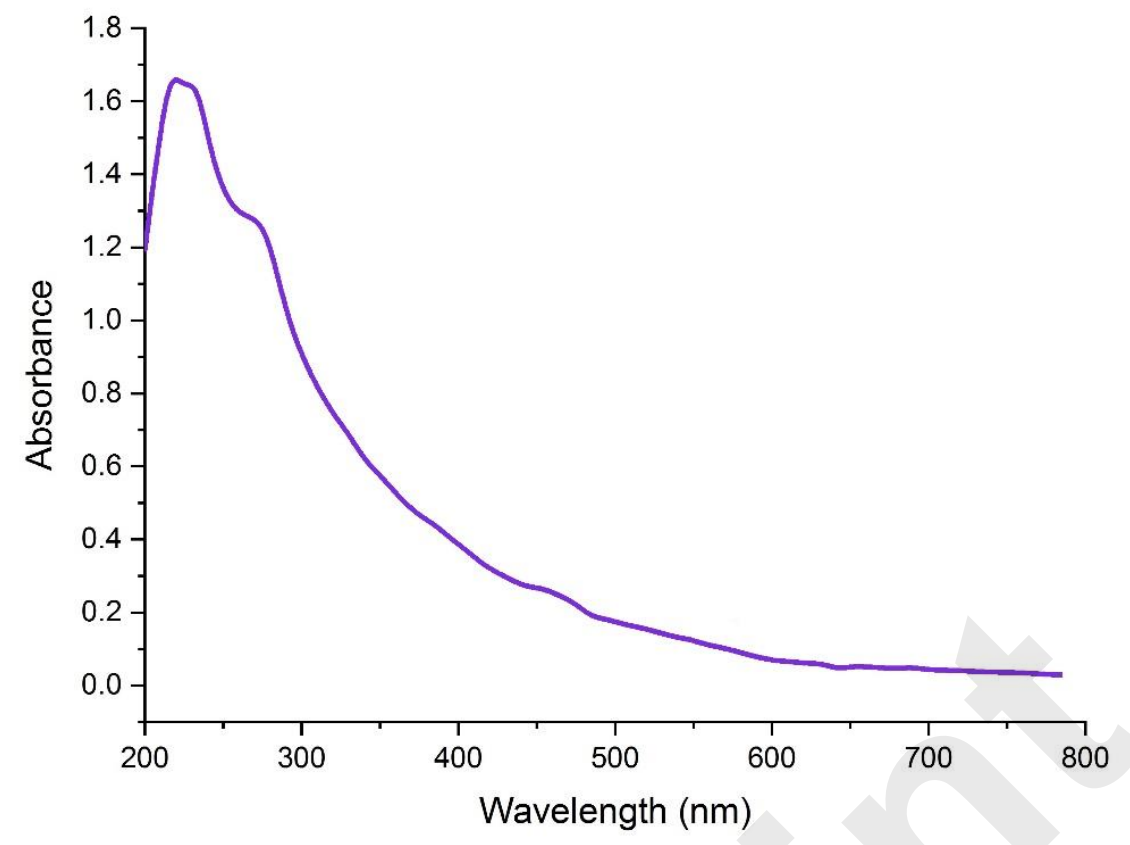

Figure 1.UV-Vis. spectra of biosynthesized TiNPs.

\section{FT-IR analysis}

Fig. 2 exhibits the spectra of TiNPs. The peaks at 503 and $582 \mathrm{~cm}^{-1}$ belong to the bending vibration of $\mathrm{Ti}-\mathrm{O}$. These peaks for $\mathrm{TiO}_{2}$ nanoparticles have been reported previously with a small difference in the wavenumber ${ }^{29}$. FT-IR technique is an acceptable method to evaluate the secondary plant metabolites as the capping and reducing agents of titanium chloride precursor to TiNPs. FT-IR spectrum of TiNPs shows the presence of different-IR bands that correlate to the presence of various functional groups in A. maurorum extract that covers the TiNPs. A broad peak around 3400 relates to O-H, peak at $2941 \mathrm{~cm}^{-1}$ shows an aliphatic $\mathrm{C}-\mathrm{H}$ stretching band. These peaks can be considered for some phytochemical compounds found in $A$. maurorum extract such as phenolic, flavonoid, triterpenes ${ }^{21,30,31}$. 


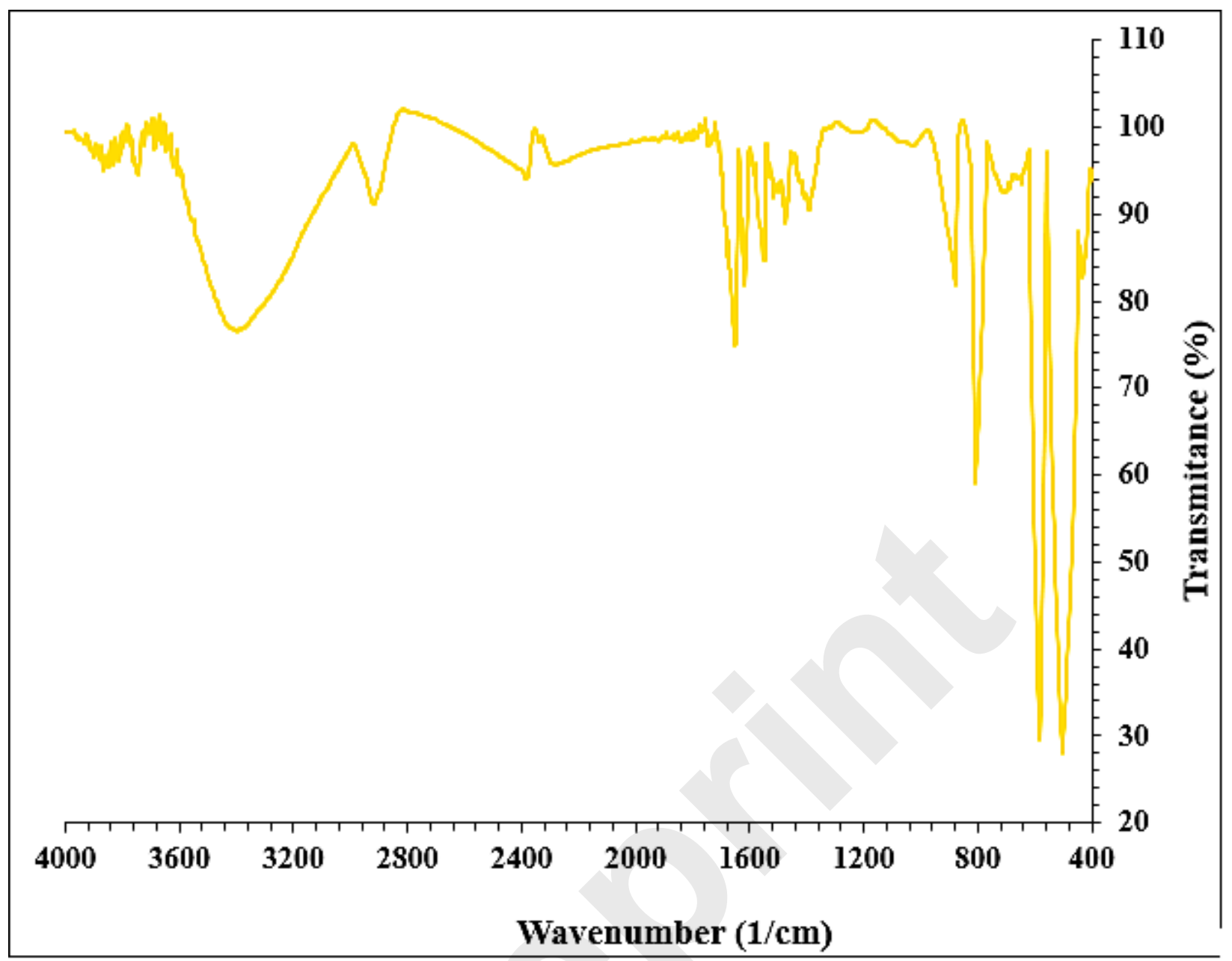

Figure 2.FT-IR Spectrum of biosynthetic TiNPs.

\section{$X R D$ analysis}

Fig. 3 shows the XRD pattern of TiNPs. The result, same to FT-IR spectra, approves the synthesis of zinc oxide. The peaks at 25.37, 38.59, 48.10, 53.97, 55.10, 62.75, and 75.17 corresponding to (101), (112), (200), (105), (211), (204), and (215) planes. These peaks are matched as well as to those of $\mathrm{TiO} 2$ nanoparticles reported previously ${ }^{27}$. The crystallinity of the TiNPs has been accepted using the XRD diffractogram. The average crystal size of TiNPs was calculated using X-ray diffraction according to the Scherrer equation (eq.1). The $\mathrm{TiO}_{2}$ nanoparticles had an average crystal size of $16.08 \mathrm{~nm}$.

$$
D=\frac{k \lambda}{\beta \cos \theta} \text { eq. } 1
$$




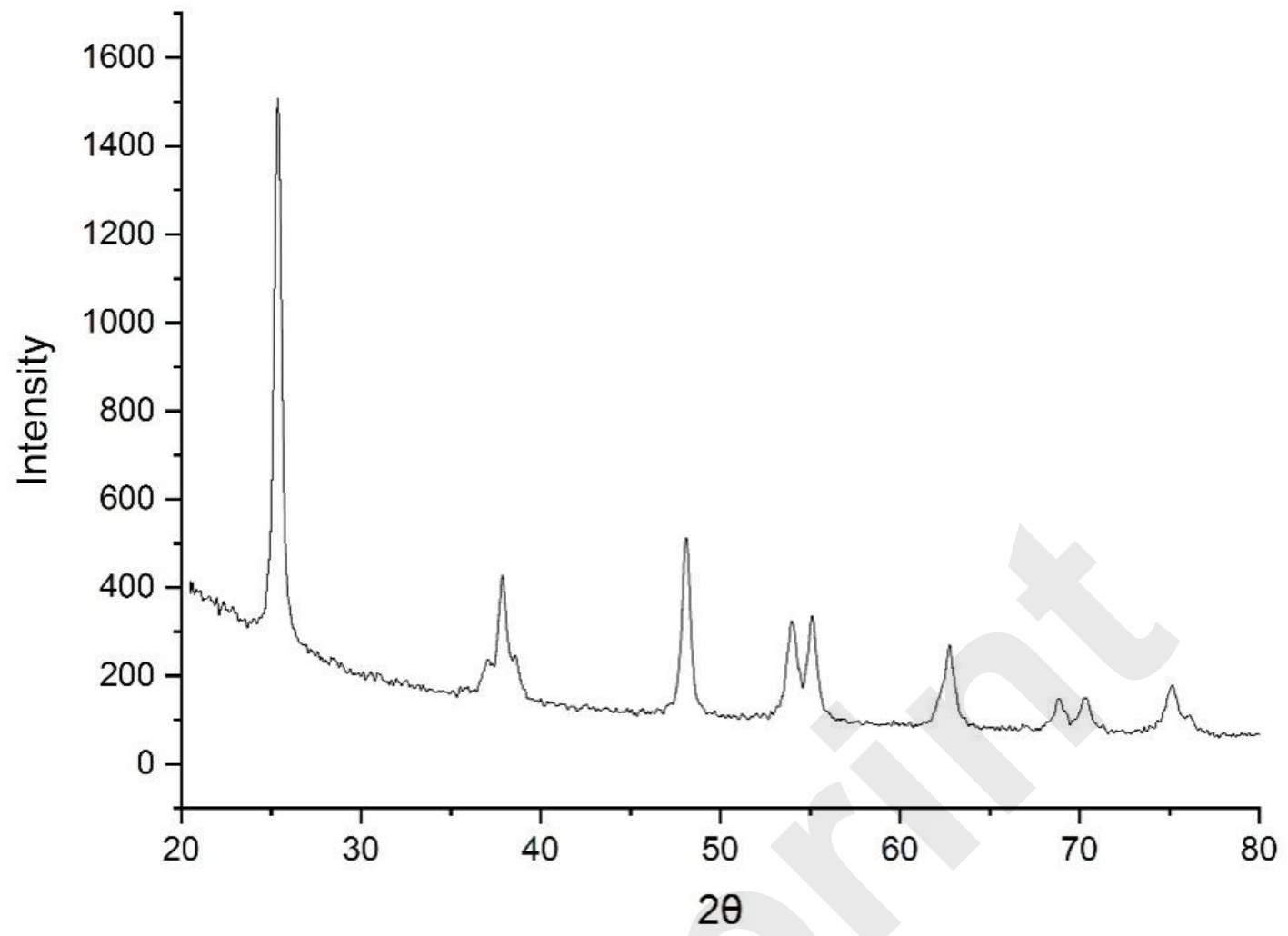

Figure 3.XRD Patternof TiONPs.

\section{SEM analysis}

Fig 4 shows the FE-SEM images of TiNPs. The images exhibited a spherical morphology for the biosynthetic of TiNPs. This morphology for biosynthesized TiNPs has been reported previously ${ }^{14}$. The particle size of TiNPs varied from 12.16 to $43.46 \mathrm{~nm}$. The figure also confirms the uniformity, well dispersed, and homogeneous of the TiNPs. The biosynthetic metallic nanoparticles such as TiNPs, ZnNPs, MnNPs, SnNPs, and AgNPs usually show a tendency to aggregate $27,32-35$. This property also is observed for the biosynthetic of TiNPs in this research. Various particle sizes, from 10 to $100 \mathrm{~nm}$, have been reported for TiNPs that were synthesized using green chemistry procedures ${ }^{11,13}$, 14, 27. 


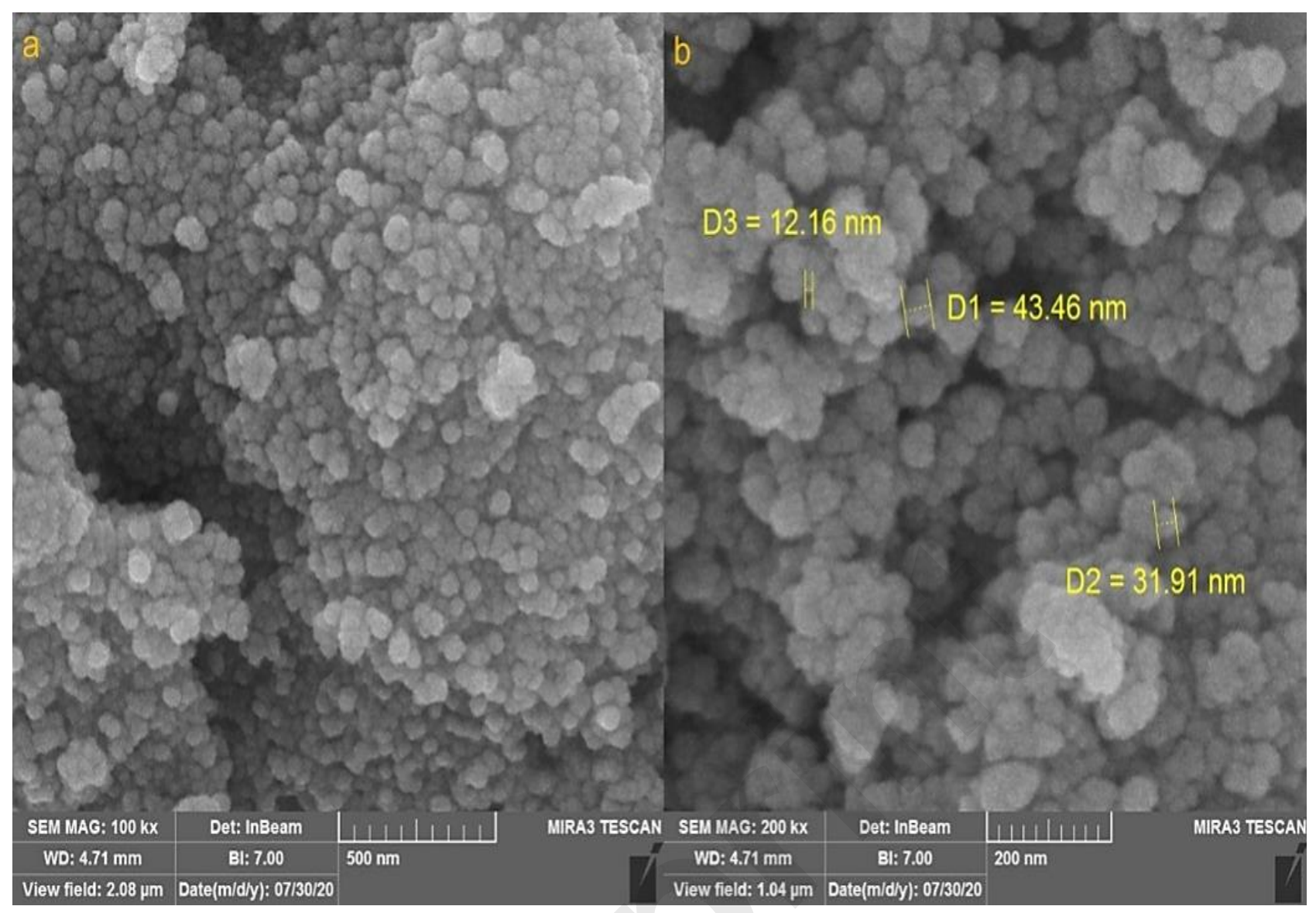

Figure 4. SEM images of TiNPs.

\section{EDS analysis}

The EDS analysis is shown in Fig. 5. EDS is a qualitative method to screen the elemental composition profile of compounds. It is based on the interaction of an X-ray beam with the sample to recognize the atomic structure of the sample. The spectrum shows the presence of titanium, oxygen, and carbon in the synthetic nanoparticles. The signal before $1 \mathrm{Kev}$ (for TiL $\alpha$ ), after $4.5 \mathrm{Kev}$ (TiKa), and below $5 \mathrm{Kev}$ (for TiK $\beta$ ). These signals are as well as match those of biosynthesized TiNPs that were reported previously ${ }^{29}$. The presence of oxygen is approved by the signal around $0.5 \mathrm{Kev}$. This signal is related to the oxygen of $\mathrm{TiO}_{2}$ and the phytochemical of. Maurorumextract. The presence of carbon on the surface of TiNPsis was also confirmed with the signal before $0.3 \mathrm{Kev}$. 


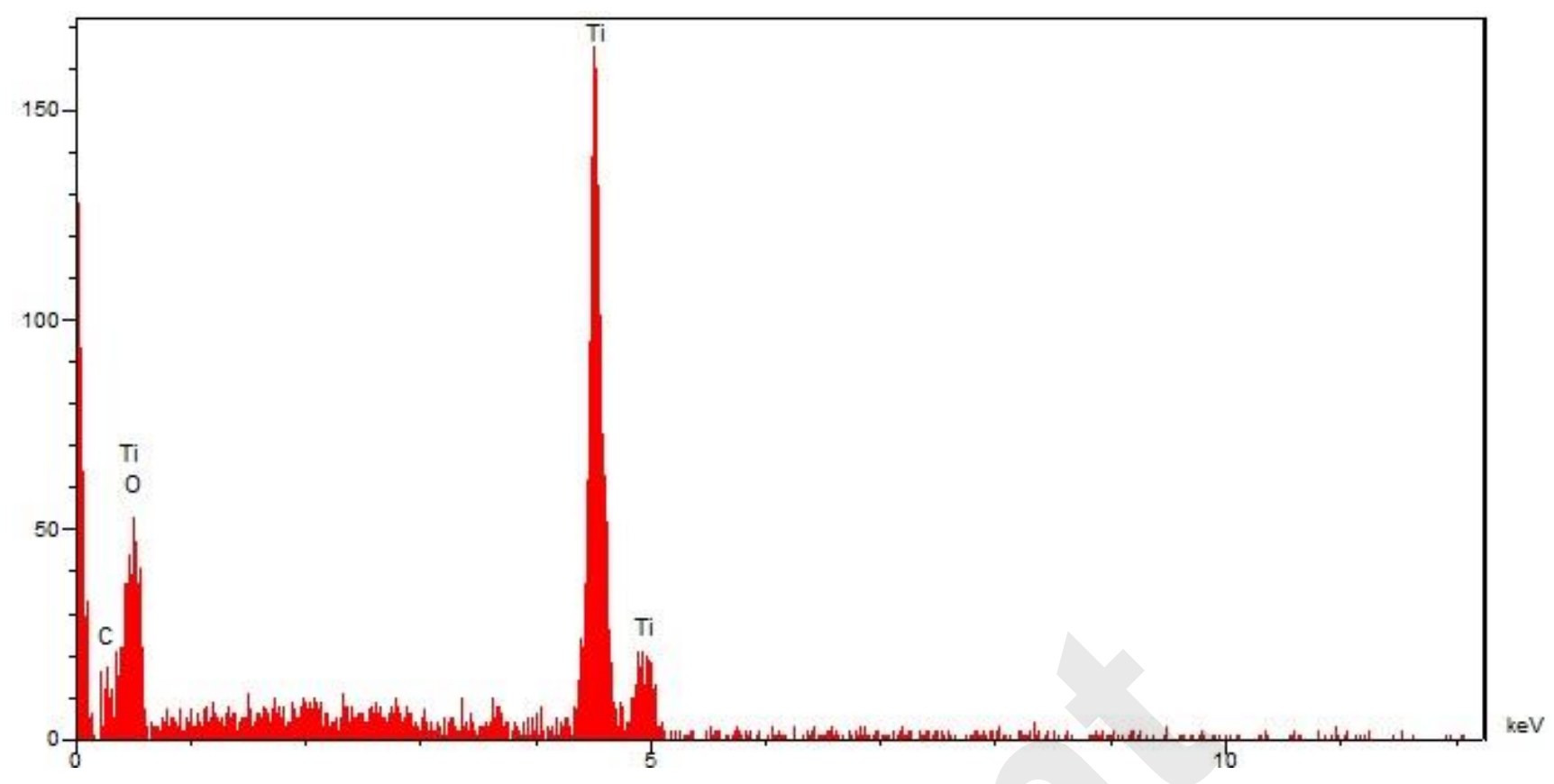

Figure 5. EDS analysis of TiNPs.

\section{Anti-human breast carcinoma effects of the titanium nanoparticles}

Despite many advances in disease control and treatment, cancer remains one of the global challenges to human health. The most common treatment for cancer is chemotherapy. An important point in the treatment of cancer with chemotherapy is the acquired resistance of the tumor to drugs, and this has created major problems for the treatment of cancer ${ }^{4,5}$. Because the rate of mutation and genetic instability in cancer cells is very high and genetic changes occur rapidly in them, these cells become resistant to drugs. Therefore, further research on discovering new treatment strategies to overcome the drug resistance of cancers seems necessary 5, 6 . Meanwhile, nanotechnology has created a promising field in the field of cancer treatment. In recent years, the anti-cancer and anti-angiogenic effects of metallic nanoparticles have been considered and the results have shown that metallic nanoparticles can be considered as a potential anti-cancer agent. Reddy et al. investigated the antioxidant, antibacterial and anticancer effects of metallic nanoparticles produced using Piper longum extract ${ }^{7}$. 
Many parameters such as surface functions nature and texture and size are important in the anticancer effects of metallic nanoparticles, of course, the efficacy of the size is the main ${ }^{8-11}$. Many reports have been indicated whatever the size of the nanoparticles is low, their ability to poring and destroying the cancer cells is more. In detail, it has been reported the nanoparticles with a size lower than $50 \mathrm{~nm}$ have the best condition for anticancer effects $^{9-14}$. As shown in the FE-SEMfigure, the size of nanoparticles is less than $40 \mathrm{~nm}$. In our research, the treated cell lines with $\mathrm{TiCl}_{4}, A$. maurorum leaf aqueous extract, and titanium nanoparticles were tested by a well-known cytotoxicity test, i.e. MTT test for 72 $\mathrm{h}$ regarding the cytotoxicity activities on normal (HUVEC) and breast cancer (Breast adenocarcinoma (MCF7), infiltrating ductal cell carcinoma (Hs 319.T), inflammatory carcinoma of the breast (UACC-732), and metastatic carcinoma (MDA-MB-453) cell lines (Table 1 and 2). $\mathrm{TiCl}_{4}, A$. maurorum leaf aqueous extract, and titanium particles didn't show any toxicity on HUVEC cells in the MTT assay.

The cell viability of breast carcinoma cells decreased dose-dependently in the $\mathrm{TiCl}_{4}, A$. maurorum leaf aqueous extract, and titanium nanoparticles presence. The IC50 of $A$. maurorum and titanium particles on MCF7 cell line were 680 and $359 \mu \mathrm{g} / \mathrm{mL}$, on Hs 319.T cell line were 507 and $191 \mu \mathrm{g} / \mathrm{mL}$, on UACC-732 cell line were 477 and $217 \mu \mathrm{g} / \mathrm{mL}$, and on MDA-MB-453cell line were 507 and $191 \mu \mathrm{g} / \mathrm{mL}$, respectively. The best findings were reported about the Hs 319.T cell line.

Likely significant anti-cancer activities of $A$. maurorum leaf aqueous extract and titanium nanoparticlesare related to their antioxidant properties. Similar reports have shown the antioxidant molecules such as metallic nanocomposites reduce the tumor volume by destroying free radicals ${ }^{36-38}$. In detail, the free radicals high presence in the normal cells cause several mutations in their RNA and DNA and increase the growth and proliferation of cancerous cells ${ }^{39,40}$. The free radicals in skin, throat, ovarian, testicular, bladder, colon, small intestine, gastrointestinal stromal, stomach, breast, lung, vaginal, prostate, pancreatic, liver, gallbladder, hypopharyngeal, fallopian tube, thyroid, esophageal, parathyroid, bile duct, and rectal cancers reveal the notable place of these radicals in causing tumorigenesis and angiogenesis ${ }^{39-42}$. 


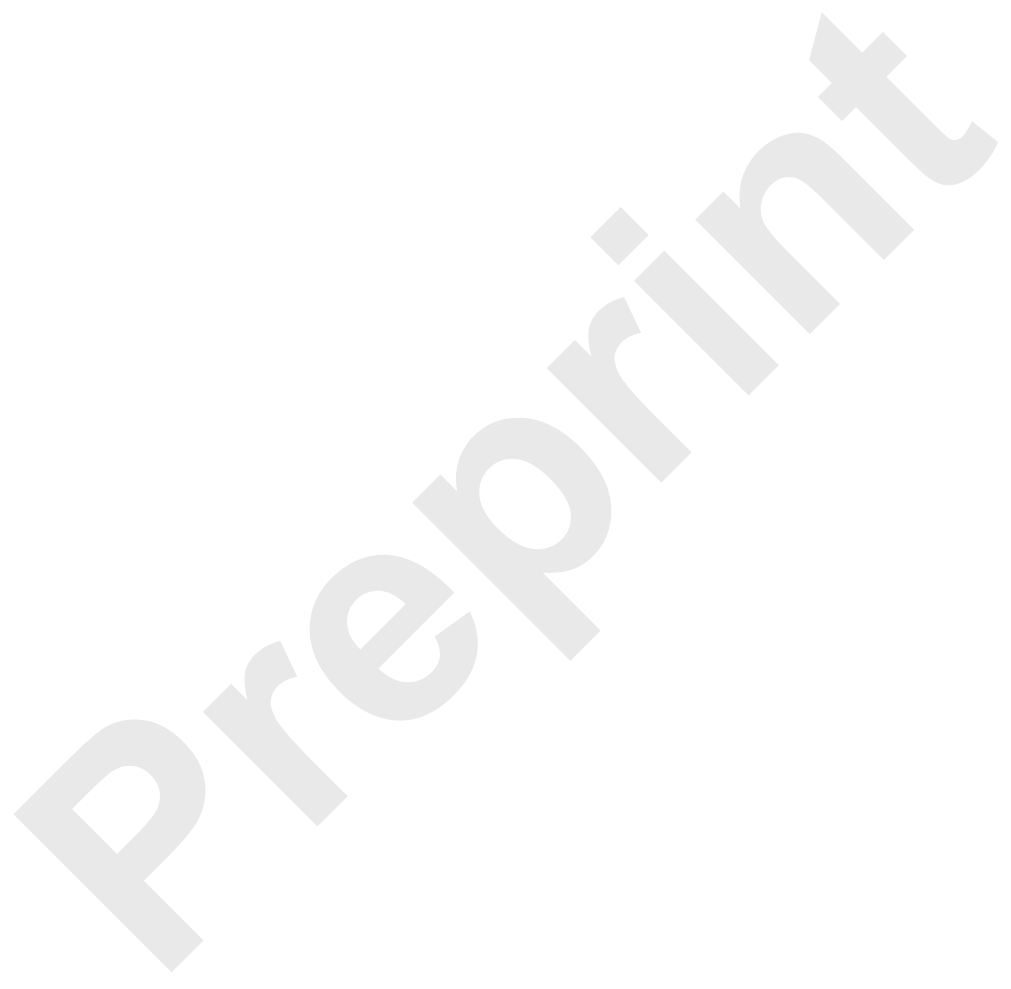


TABLE 1The anti-breast carcinoma properties of $\mathrm{TiCl}_{4}, A$. maurorum leaf aqueous extract, and TiNPs against human breast carcinoma cell line.

\begin{tabular}{|c|c|c|c|c|c|}
\hline \multirow{2}{*}{$\begin{array}{c}\text { Concentration } \\
(\mu \mathrm{g} / \mathrm{ml})\end{array}$} & \multicolumn{5}{|c|}{ Cell Viability (\%) } \\
\hline & HUVEC & MDA-MB-453 & MCF7 & UACC-732 & Hs 319.T \\
\hline $\mathrm{TiCl}_{4}(0)$ & $100 \pm 0^{\mathrm{a}}$ & $100 \pm 0^{\mathrm{a}}$ & $100 \pm 0^{\mathrm{a}}$ & $100 \pm 0^{\mathrm{a}}$ & $100 \pm 0^{\mathrm{a}}$ \\
\hline $\mathrm{TiCl}_{4}(\mathbf{1})$ & $100 \pm 0^{\mathrm{a}}$ & $100 \pm 0^{a}$ & $100 \pm 0^{a}$ & $100 \pm 0^{\mathrm{a}}$ & $100 \pm 0^{a}$ \\
\hline $\mathrm{TiCl}_{4}(2)$ & $100 \pm 0^{\mathrm{a}}$ & $100 \pm 0^{\mathrm{a}}$ & $100 \pm 0^{a}$ & $100 \pm 0^{\mathrm{a}}$ & $100 \pm 0^{a}$ \\
\hline $\mathrm{TiCl}_{4}(\mathbf{3})$ & $100 \pm 0^{a}$ & $100 \pm 0^{a}$ & $100 \pm 0^{a}$ & $100 \pm 0^{a}$ & $100 \pm 0^{a}$ \\
\hline $\mathrm{TiCl}_{4}(7)$ & $99.6 \pm 0.89^{a}$ & $100 \pm 0^{a}$ & $100 \pm 0^{a}$ & $100 \pm 0^{a}$ & $100 \pm 0^{a}$ \\
\hline $\mathrm{TiCl}_{4}(15)$ & $97.2 \pm 1.3^{\mathrm{a}}$ & $99.4 \pm 0.89^{a}$ & $98.2 \pm 1.3^{a}$ & $99.4 \pm 0.54^{a}$ & $98 \pm 1.22^{\mathrm{a}}$ \\
\hline $\mathrm{TiCl}_{4}(31)$ & $94.2 \pm 0.44^{a}$ & $97.2 \pm 0.83^{a}$ & $96 \pm 1.22^{\mathrm{a}}$ & $97.6 \pm 0.89^{a}$ & $96.4 \pm 0.89^{a}$ \\
\hline $\mathrm{TiCl}_{4}(62)$ & $90.4 \pm 0.89^{a}$ & $94 \pm 0.7^{a}$ & $93.6 \pm 1.14^{a}$ & $93.2 \pm 0.83^{a}$ & $91.2 \pm 0.44^{\mathrm{a}}$ \\
\hline $\mathrm{TiCl}_{4}(\mathbf{1 2 5})$ & $85.4 \pm 0.54^{\mathrm{a}}$ & $88.2 \pm 0.44^{a}$ & $88.2 \pm 1.3^{\mathrm{a}}$ & $87.6 \pm 1.14^{\mathrm{a}}$ & $85.4 \pm 0.89^{a}$ \\
\hline $\mathrm{TiCl}_{4}(250)$ & $79.6 \pm 1.14^{\mathrm{ab}}$ & $80 \pm 1.22^{\mathrm{ab}}$ & $78.2 \pm 0.44^{\mathrm{ab}}$ & $77.4 \pm 0.89^{\mathrm{ab}}$ & $76.6 \pm 1.14^{\mathrm{ab}}$ \\
\hline $\mathrm{TiCl}_{4}(500)$ & $73 \pm 1.22^{\mathrm{ab}}$ & $72 \pm 0.7^{\mathrm{ab}}$ & $67 \pm 1^{\mathrm{ab}}$ & $67.2 \pm 0.83^{\mathrm{ab}}$ & $65.6 \pm 1.14^{\mathrm{ab}}$ \\
\hline $\mathrm{TiCl}_{4}(\mathbf{1 0 0 0})$ & $62 \pm 0.7^{\mathrm{ab}}$ & $60.6 \pm 0.89^{b}$ & $55.2 \pm 0.44^{b}$ & $52.4 \pm 0.89^{b}$ & $51.2 \pm 1.3^{b}$ \\
\hline A. maurorum (0) & $100 \pm 0^{\mathrm{a}}$ & $100 \pm 0^{\mathrm{a}}$ & $100 \pm 0^{a}$ & $100 \pm 0^{\mathrm{a}}$ & $100 \pm 0^{\mathrm{a}}$ \\
\hline A. maurorum(1) & $100 \pm 0^{a}$ & $100 \pm 0^{\mathrm{a}}$ & $100 \pm 0^{\mathrm{a}}$ & $100 \pm 0^{a}$ & $100 \pm 0^{a}$ \\
\hline A. maurorum(2) & $100 \pm 0^{a}$ & $100 \pm 0^{\mathrm{a}}$ & $100 \pm 0^{\mathrm{a}}$ & $100 \pm 0^{\mathrm{a}}$ & $100 \pm 0^{a}$ \\
\hline A. maurorum(3) & $100 \pm 0^{a}$ & $100 \pm 0^{\mathrm{a}}$ & $100 \pm 0^{a}$ & $100 \pm 0^{\mathrm{a}}$ & $100 \pm 0^{\mathrm{a}}$ \\
\hline A. maurorum(7) & $100 \pm 0^{\mathrm{a}}$ & $98.4 \pm 0.54^{a}$ & $100 \pm 0^{\mathrm{a}}$ & $99.2 \pm 1.3^{\mathrm{a}}$ & $99 \pm 0.7^{\mathrm{a}}$ \\
\hline A. maurorum(15) & $100 \pm 0^{\mathrm{a}}$ & $95.2 \pm 0.44^{a}$ & $99.6 \pm 0.89^{\mathrm{a}}$ & $96 \pm 1^{\mathrm{a}}$ & $96.2 \pm 0.83^{\mathrm{a}}$ \\
\hline A. maurorum(31) & $99.4 \pm 0.54^{a}$ & $91.6 \pm 1.14^{a}$ & $95.2 \pm 0.44^{a}$ & $90.2 \pm 0.44^{\mathrm{a}}$ & $92.4 \pm 0.54^{a}$ \\
\hline A. maurorum(62) & $98 \pm 1.22^{\mathrm{a}}$ & $84.6 \pm 1.14^{\mathrm{a}}$ & $89 \pm 1.22^{\mathrm{a}}$ & $82.4 \pm 0.89^{a}$ & $85.6 \pm 1.14^{a}$ \\
\hline A. maurorum(125) & $96.4 \pm 0.89^{a}$ & $77 \pm 1^{\mathrm{ab}}$ & $81.2 \pm 0.83^{a}$ & $73.4 \pm 0.89^{\mathrm{ab}}$ & $78.2 \pm 1.3^{\mathrm{ab}}$ \\
\hline A. maurorum(250) & $94.2 \pm 0.44^{a}$ & $67.6 \pm 1.14^{\mathrm{ab}}$ & $70.6 \pm 0.89^{\mathrm{ab}}$ & $61.4 \pm 0.54^{\mathrm{ab}}$ & $65 \pm 1^{\mathrm{ab}}$ \\
\hline A. maurorum(500) & $91.4 \pm 0.54^{\mathrm{a}}$ & $52.2 \pm 0.83^{b}$ & $57.2 \pm 0.44^{\mathrm{b}}$ & $48.2 \pm 1.3^{b}$ & $50.2 \pm 0.44^{b}$ \\
\hline A. maurorum(1000) & $86.2 \pm 1.3^{\mathrm{a}}$ & $34 \pm 0.7^{\mathrm{bc}}$ & $38.2 \pm 1.3^{\mathrm{bc}}$ & $29.6 \pm 1.14^{\mathrm{bc}}$ & $31.2 \pm 0.44^{\mathrm{bc}}$ \\
\hline TiNPs (0) & $100 \pm 0^{\mathrm{a}}$ & $100 \pm 0^{\mathrm{a}}$ & $100 \pm 0^{\mathrm{a}}$ & $100 \pm 0^{\mathrm{a}}$ & $100 \pm 0^{\mathrm{a}}$ \\
\hline TiNPs (1) & $100 \pm 0^{a}$ & $100 \pm 0^{\mathrm{a}}$ & $100 \pm 0^{a}$ & $100 \pm 0^{a}$ & $100 \pm 0^{a}$ \\
\hline TiNPs (2) & $100 \pm 0^{a}$ & $100 \pm 0^{a}$ & $100 \pm 0^{a}$ & $99.2 \pm 1.3^{a}$ & $98.2 \pm 0.83^{a}$ \\
\hline TiNPs (3) & $100 \pm 0^{a}$ & $99.6 \pm 1.14^{a}$ & $98.2 \pm 0.44^{a}$ & $96 \pm 1.22^{\mathrm{a}}$ & $96.4 \pm 0.89^{a}$ \\
\hline TiNPs (7) & $100 \pm 0^{a}$ & $97.6 \pm 0.89^{a}$ & $96 \pm 0.7^{\mathrm{a}}$ & $92.6 \pm 1.14^{a}$ & $92.2 \pm 1.3^{\mathrm{a}}$ \\
\hline TiNPs (15) & $100 \pm 0^{a}$ & $92.4 \pm 0.89^{a}$ & $91.2 \pm 0.83^{a}$ & $86.6 \pm 0.89^{a}$ & $87.4 \pm 0.89^{a}$ \\
\hline TiNPs (31) & $99.2 \pm 0.83^{a}$ & $85 \pm 1^{a}$ & $85.4 \pm 0.89^{a}$ & $79.2 \pm 0.44^{\mathrm{ab}}$ & $78.4 \pm 0.54^{\mathrm{ab}}$ \\
\hline TiNPs (62) & $97.4 \pm 0.89^{a}$ & $76.6 \pm 1.14^{\mathrm{ab}}$ & $76.4 \pm 0.89^{\mathrm{ab}}$ & $70.6 \pm 1.14^{\mathrm{ab}}$ & $67.4 \pm 0.89^{\mathrm{ab}}$ \\
\hline TiNPs (125) & $94.4 \pm 0.54^{a}$ & $65.2 \pm 0.44^{\mathrm{ab}}$ & $66 \pm 1.22^{\mathrm{ab}}$ & $59.4 \pm 0.54^{\mathrm{b}}$ & $56.2 \pm 1.3^{\mathrm{b}}$ \\
\hline TiNPs (250) & $90.2 \pm 1.3^{\mathrm{a}}$ & $53.2 \pm 0.83^{b}$ & $57.6 \pm 0.89^{b}$ & $48 \pm 0.7^{b}$ & $44 \pm 1^{b}$ \\
\hline TiNPs (500) & $85 \pm 1.22^{\mathrm{a}}$ & $38 \pm 0.7^{\mathrm{bc}}$ & $42 \pm 0.7^{b}$ & $35.6 \pm 1.14^{\mathrm{bc}}$ & $29.2 \pm 0.83^{\mathrm{bc}}$ \\
\hline TiNPs (1000) & $78.6 \pm 0.89^{\mathrm{ab}}$ & $16.2 \pm 0.44^{\mathrm{c}}$ & $24.6 \pm 1.14^{\mathrm{bc}}$ & $12.2 \pm 0.44^{\mathrm{c}}$ & $10.6 \pm 0.89^{c}$ \\
\hline
\end{tabular}

The various words report significant differences between examined groups $(P \leq 0.01)$. 
TABLE 2 The IC50 of $\mathrm{TiCl}_{4}, A$. maurorum leaf aqueous extract, and TiNPsin cytotoxicity and anti-breast carcinoma tests.

\begin{tabular}{|l|c|c|c|}
\hline & $\mathrm{TiCl}_{4}(\mu \mathrm{g} / \mathrm{mL})$ & $\begin{array}{c}A . \\
\text { maurorum }(\mu \mathrm{g} / \mathrm{mL})\end{array}$ & \\
\hline IC50 against HUVEC & - & - & - \\
\hline $\begin{array}{l}\text { IC50 against MDA-MB- } \\
\mathbf{4 5 3}\end{array}$ & - & $564 \pm 0^{\mathrm{b}}$ & $297 \pm 0^{\mathrm{d}}$ \\
\hline IC50 against MCF7 & - & & $359 \pm 0^{\mathrm{d}}$ \\
\hline IC50 against UACC-732 & - & $477 \pm 0^{\mathrm{c}}$ & $217 \pm 0^{\mathrm{e}}$ \\
\hline IC50 against Hs 319.T & - & $507 \pm 0^{\mathrm{bc}}$ & $191 \pm 0^{\mathrm{e}}$ \\
\hline
\end{tabular}

The various words report significant differences between examined groups $(P \leq 0.01)$.

\section{CONCLUSION}

In this research, the titanium nanoparticles were attained from the reaction between 25 milliliters of the extract and $100 \mathrm{ml}$ of $0.1 \mathrm{M}$ aqueous solution of $\mathrm{TiCl}_{4}$. FE-SEM, UV-Vis, EDS, XRD, and FT-IR methods were utilized to evaluate nanoparticles characteristics. The results of these techniques revealed that titanium nanoparticles had been synthesized in the best way. Base on the FT-IR spectrum the presence of a great number of antioxidant compounds produced appropriate conditions for the reduction of titanium. In the FE-SEM technique, the range size of titanium nanoparticles was assessed to be 12.16 to $43.46 \mathrm{~nm}$, which is favorable. The titanium nanoparticles had appropriate antihuman breast carcinoma activities dose-dependently against breast cancer (Breast adenocarcinoma (MCF7), infiltrating ductal cell carcinoma (Hs 319.T), inflammatory carcinoma of the breast (UACC-732), and metastatic carcinoma (MDA-MB-453)) cell lines without any cytotoxicity on the normal cell line (HUVEC). After clinical study titanium nanoparticles containing $A$. maurorum leaf aqueous extract can be utilized as an efficient drug/supplement in treating breast cancer and diseases in humans. 
Ethics approval: No humans or animals are included in this study.

Consent for publication: All the authors consented to the publication of this article.

Availability of data and materials: The data used to support the findings of this study are included in the article. Additional data or information can be requested by contacting the corresponding author.

Competing interests: No potential competing interests relevant to this study were reported.

Acknowledgments: We wish to thank the sponsors for the following grants

Key Project supported by Medical Science and technology development Foundation, Nanjing Department of Health (YKK16078)

Key Project supported by Medical Science and technology development Foundation, Nanjing Department of Health (YKK18040)

National Natural Science Foundation of China (81271997)

\section{References}

1. Bray F, Ferlay J, Soerjomataram I, Siegel RL, Torre LA and Jemal A, Global cancer statistics 2018: GLOBOCAN estimates of incidence and mortality worldwide for 36 cancers in 185 countries. CA: a cancer journal for clinicians 68:394-424 (2018).

2. Boyd NF, Guo H, Martin LJ, Sun L, Stone J, Fishell E, Jong RA, Hislop G, Chiarelli A and Minkin S, Mammographic density and the risk and detection of breast cancer. New England journal of medicine 356:227-236 (2007).

3. Siu AL, Screening for breast cancer: US Preventive Services Task Force recommendation statement. Annals of internal medicine 164:279-296 (2016).

4. Jahanzeb M, Adjuvant trastuzumab therapy for HER2-positive breast cancer. Clinical breast cancer 8:324-333 (2008).

5. (a) Jabłońska J, Cielecka-Kuszyk J, Mikuła T, Kozłowska J, WiercińskaDrapało A. Hepatopathy of unknown etiology - is liver biopsy a good tool in differential diagnosis? Arch Med Sci. 2019;15(6):1462-1467. (b) KaczmarczykSedlak I, Folwarczna J, Sedlak L, Zych M, Wojnar W, Szumińska I, WyględowskaPromieńska D, Mrukwa-Kominek E. Effect of caffeine on biomarkers of oxidative stress in lenses of rats with streptozotocin-induced diabetes. Arch Med Sci 2019;15(4):1073-1080. (c) Kayar Y, Agin M. The relationship between demographic and anthropometric characteristics and diabetic complications and number of hospitalizations in hospitalized diabetic patients. Arch Med Sci Civil Dis. 2019;4:e7-e15. (d) Michalak SS, Rupa-Matysek J, Hus I, Gil L. Unexplained anemia in the elderly - a real life analysis of 981 patients. Arch Med Sci 2020;16(4):834- 
841. (e) Szymusik I, Kosinska-Kaczynska K, Krowicka M, Sep M, Marianowski P, Wielgos M. Perinatal outcome of in vitro fertilization singletons - 10 years' experience of one center. Arch Med Sci 2019;15(3):666-672.

6. Li Y, Li N, Jiang W, Ma G and Zangeneh MM, In situ decorated Au NPs on pectinmodified Fe3O4 NPs as a novel magnetic nanocomposite (Fe3O4/Pectin/Au) for catalytic reduction of nitroarenes and investigation of its anti-human lung cancer activities. International Journal of Biological Macromolecules 163:2162-2171 (2020).

7. Reddy NJ, Vali DN, Rani M and Rani SS, Evaluation of antioxidant, antibacterial and cytotoxic effects of green synthesized silver nanoparticles by Piper longum fruit. Materials Science and Engineering: C 34:115-122 (2014).

8. Fahimmunisha BA, Ishwarya R, AISalhi MS, Devanesan S, Govindarajan M and Vaseeharan B, Green fabrication, characterization and antibacterial potential of zinc oxide nanoparticles using Aloe socotrina leaf extract: A novel drug delivery approach. Journal of Drug Delivery Science and Technology 55:101465 (2020).

9. Rosi $\mathrm{H}$ and Kalyanasundaram S, Synthesis, characterization, structural and optical properties of titanium-dioxide nanoparticles using Glycosmis cochinchinensis Leaf extract and its photocatalytic evaluation and antimicrobial properties. World News of Natural Sciences An International Sientific Journal 17 (2018).

10. Jalill A, Raghad D, Nuaman RS and Abd AN, Biological synthesis of Titanium Dioxide nanoparticles by Curcuma longa plant extract and study its biological properties. World Scientific News 49:204-222 (2016).

11. Dobrucka R, The biological synthesis of anatase titanium dioxide nanoparticles using Arnicae anthodium extract. Bulgarian Chemical Communications 49:595-599 (2017).

12. Abd El-Haliem NG, The possible role of milk thistle extract on titanium dioxide nanoparticles-induced lung toxicity in male albino rat: a histological and immunohistochemical study. Egyptian journal of histology 39:179-190 (2016).

13. Sundrarajan M, Bama K, Bhavani M, Jegatheeswaran S, Ambika S, Sangili A, Nithya $\mathrm{P}$ and Sumathi $\mathrm{R}$, Obtaining titanium dioxide nanoparticles with spherical shape and antimicrobial properties using $M$. citrifolia leaves extract by hydrothermal method. Journal of Photochemistry and Photobiology B: Biology 171:117-124 (2017).

14. Saravanan S, Balamurugan M, Lippitz A, Fonda E and Swaraj S, XANES studies of titanium dioxide nanoparticles synthesized by using Peltophorum pterocarpum plant extract. Physica B: Condensed Matter 503:86-92 (2016).

15. Rashidi K, Mahmoudi M, Mohammadi G, Zangeneh MM, Korani S, Goicoechea $\mathrm{HC}, \mathrm{Gu} \mathrm{H-W}$ and Jalalvand AR, Simultaneous co-immobilization of three enzymes onto a modified glassy carbon electrode to fabricate a high-performance amperometric biosensor for determination of total cholesterol. International journal of biological macromolecules 120:587-595 (2018).

16. Goorani S, Shariatifar N, Seydi N, Zangeneh A, Moradi R, Tari B, Nazari F and Zangeneh MM, The aqueous extract of Allium saralicum RM Fritsch effectively treat 
induced anemia: experimental study on Wistar rats. Oriental Pharmacy and Experimental Medicine 19:403-413 (2019).

17. Sayyedrostami T, Pournaghi P, Vosta-Kalaee SE and Zangeneh MM, Evaluation of the wound healing activity of Chenopodium botrys leaves essential oil in rats (a shortterm study). Journal of Essential Oil Bearing Plants 21:164-174 (2018).

18. Awaad Amani A, Maitland D and Soliman G, Antiulcerogenic Activity of Alhagi maurorum. Pharmaceutical biology 44:292-296 (2006).

19. Shaker E, Mahmoud $\mathrm{H}$ and Mnaa S, Anti-inflammatory and anti-ulcer activity of the extract from Alhagi maurorum (camelthorn). Food and Chemical Toxicology 48:27852790 (2010).

20. Atta AH and Mouneir SM, Antidiarrhoeal activity of some Egyptian medicinal plant extracts. Journal of Ethnopharmacology 92:303-309 (2004).

21. Laghari AH, Ali Memon A, Memon S, Nelofar A, Khan KM and Yasmin A, Determination of free phenolic acids and antioxidant capacity of methanolic extracts obtained from leaves and flowers of camel thorn (Alhagi maurorum). Natural product research 26:173-176 (2012).

22. Laghari AH, Memon S, Nelofar A, Khan KM, Yasmin A, Syed MN and Aman A, A new flavanenol with urease-inhibition activity isolated from roots of manna plant camelthorn (Alhagi maurorum). Journal of Molecular Structure 965:65-67 (2010).

23. Almeida R, Navarro D and Barbosa-Filho J, Plants with central analgesic activity. Phytomedicine 8:310-322 (2001).

24. Abu-Dahab R and Afifi F, Antiproliferative activity of selected medicinal plants of Jordan against a breast adenocarcinoma cell line (MCF7). Scientia Pharmaceutica 75:121-146 (2007).

25. Laghari AH, Memon S, Nelofar A and Khan KM, Alhagi maurorum: a convenient source of lupeol. Industrial crops and products 34:1141-1145 (2011).

26. Atta A and El-Sooud KA, The antinociceptive effect of some Egyptian medicinal plant extracts. Journal of ethnopharmacology 95:235-238 (2004).

27. Seydi N, Mahdavi B, Paydarfard S, Zangeneh A, Zangeneh MM, Najafi F, Jalalvand $A R$ and Pirabbasi E, Preparation, characterization, and assessment of cytotoxicity, antioxidant, antibacterial, antifungal, and cutaneous wound healing properties of titanium nanoparticles using aqueous extract of Ziziphora clinopodioides Lam leaves. Applied Organometallic Chemistry 33:e5009 (2019).

28. Seyedalipour B, Pourakbar E and Taravati A, The Cytotoxic Effect of Ethanolic Extract of Pistacia Khinjuk Leaf onHeLa and MCF-7 Cancerous Cell Lines. Journal of Rafsanjan University of Medical Sciences 14:939-952 (2016).

29. Rostami-Vartooni A, Nasrollahzadeh M, Salavati-Niasari M and Atarod M, Photocatalytic degradation of azo dyes by titanium dioxide supported silver nanoparticles prepared by a green method using Carpobrotus acinaciformis extract. Journal of Alloys and Compounds 689:15-20 (2016). 
30. Akbar S, Handbook of 200 Medicinal Plants: A Comprehensive Review of Their Traditional Medical Uses and Scientific Justifications. Springer Nature (2020).

31. Behbahani M, Evaluation of in vitro anticancer activity of Ocimum basilicum, Alhagi maurorum, Calendula officinalis and their parasite Cuscuta campestris. PloS one 9:e116049 (2014).

32. Mahdavi B, Paydarfard S, Zangeneh MM, Goorani S, Seydi N and Zangeneh A, Assessment of antioxidant, cytotoxicity, antibacterial, antifungal, and cutaneous wound healing activities of green synthesized manganese nanoparticles using Ziziphora clinopodioides Lam leaves under in vitro and in vivo condition. Applied Organometallic Chemistry 34:e5248 (2020).

33. Mahdavi B, Saneei S, Qorbani M, Zhaleh M, Zangeneh A, Zangeneh MM, Pirabbasi E, Abbasi N and Ghaneialvar H, Ziziphora clinopodioides Lam leaves aqueous extract mediated synthesis of zinc nanoparticles and their antibacterial, antifungal, cytotoxicity, antioxidant, and cutaneous wound healing properties under in vitro and in vivo conditions. Applied Organometallic Chemistry 33:e5164 (2019).

34. Baghayeri M, Mahdavi B, Hosseinpor-Mohsen Abadi Z and Farhadi S, Green synthesis of silver nanoparticles using water extract of Salvia leriifolia: Antibacterial studies and applications as catalysts in the electrochemical detection of nitrite. Applied Organometallic Chemistry 32:e4057 (2018).

35. Ahmeda A, Mahdavi B, Zaker F, Kaviani S, Hosseini S, Zangeneh MM, Zangeneh A, Paydarfar S and Moradi R, Chemical characterization and anti-hemolytic anemia potentials of tin nanoparticles synthesized by a green approach for bioremediation applications. Applied Organometallic Chemistry 34:e5433 (2020).

36. Ishino K, Wakita C, Shibata T, Toyokuni S, Machida S, Matsuda S, Matsuda T and Uchida K, Lipid peroxidation generates body odor component trans-2-nonenal covalently bound to protein in vivo. Journal of Biological Chemistry 285:15302-15313 (2010).

37. Namvar F, Rahman HS, Mohamad R, Baharara J, Mahdavi M, Amini E, Chartrand MS and Yeap SK, Cytotoxic effect of magnetic iron oxide nanoparticles synthesized via seaweed aqueous extract. International Journal of Nanomedicine 9:2479 (2014).

38. Beheshtkhoo N, Kouhbanani MAJ, Savardashtaki A, Amani AM and Taghizadeh $\mathrm{S}$, Green synthesis of iron oxide nanoparticles by aqueous leaf extract of Daphne mezereum as a novel dye removing material. Applied Physics A 124:363 (2018).

39. Radini IA, Hasan N, Malik MA and Khan Z, Biosynthesis of iron nanoparticles using Trigonella foenum-graecum seed extract for photocatalytic methyl orange dye degradation and antibacterial applications. Journal of Photochemistry and Photobiology B: Biology 183:154-163 (2018).

40. Erdemir F, Celepci DB, Aktaş A, Gök Y, Kaya R, Taslimi P, Demir Y and Gulçin I, Novel 2-aminopyridine liganded Pd (II) N-heterocyclic carbene complexes: synthesis, characterization, crystal structure and bioactivity properties. Bioorganic chemistry 91:103134 (2019).

41. Erdemir F, Celepci DB, Aktaş A, Taslimi P, Gök Y, Karabıyık H and Gülçin İ, 2Hydroxyethyl substituted NHC precursors: synthesis, characterization, crystal structure 
and carbonic anhydrase, $\alpha$-glycosidase, butyrylcholinesterase, and acetylcholinesterase inhibitory properties. Journal of molecular structure 1155:797-806 (2018).

42. Demir Y, Taslimi P, Ozaslan MS, Oztaskin N, Çetinkaya Y, Gulçin İ, Beydemir Ş and Goksu S, Antidiabetic potential: In vitro inhibition effects of bromophenol and diarylmethanones derivatives on metabolic enzymes. Archiv der pharmazie 351:1800263 (2018). 